\title{
OCAÑA, Alexander Ortiz; LÓPEZ, María Isabel Arias; CONEDO, Zaira Esther Pedrozo. Decolonialidad de la educación. Emergencia/urgencia de uma pedagogía decolonial. Santa Marta/Colômbia, Universidad del Magdalena, 2018.
}

\author{
Maurício Silva \\ Universidade Nove de Julho - UNINOVE \\ São Paulo, SP - Brasil. \\ Para citar- (ABNT NBR 6023:2018) \\ maurisil@gmail.com \\ SILVA, Maurício. Resenha. Eccos - Revista Cientifica, São Paulo, n. 58, p. 1-5, e19819, jul./set., \\ 2021. OCAÑA, Alexander Ortiz; LÓPEZ, María Isabel Arias; CONEDO, Zaira Esther Pedrozo. \\ Decolonialidad de la educación. Emergencia/urgencia de uma pedagogía decolonial. Santa \\ Marta/Colômbia, Universidad del Magdalena, 2018. Disponível em: \\ https://doi.org/10.5585/eccos.n58.19819.
}

Doutor

Cada vez mais os conceitos de colonialidade e decolonialidade ocupam espaço nas pesquisas acadêmicas, gerando uma série crescente de novas categorias, noções, métodos, princípios e conceitos, muitos deles voltados à interpretação da realidade sociocultural e política de países que se encontram à margem da globalização excludente que se verifica na contemporaneidade, em especial no continente latinoamericano.

Um dos conceitos mais produtivos, proveniente da reflexão continuada acerca das implicações que a colonialidade/decolonialidade em nossa vida cotidiana é o de pedagogia decolonial, já bastante explorado em livros e artigos, mas ainda necessitando de maior divulgação e, principalmente, aplicação em nosso meio. Trata-se de um conceito que, entre outras coisas, prevê, segundo Luiz Fernandes Oliveira (2016), "a construção de um novo espaço epistemológico que promove a interação entre conhecimentos subalternizados e ocidentais, questionando a hegemonia destes e a invizibilização daqueles" (p. 3). Formulada por Catherine Walsh, professora e pesquisadora norte-americana radicada no Equador, a pedagogia colonial diz respeito a uma intervenção política e pedagógica a partir dos pressupostos do pensamento decolonial; trata-se, em outros termos, de um trabalho de politização da ação pedagógica (WALSH, OLIVEIRA \& CANDAU, 2018).

Esse é também o tema principal, mas não exclusivo, do livro Decolonialidad de la educación. Emergencia/urgencia de uma pedagogía decolonial, escrito pelos pesquisadores 
colombianos Alexander Ocaña, María Isabel López e Zaira Pedrozo Conedo, da Universidad del Magdalena, em Santa Marta. Nele, os autores começam lembrando que a história da ciência e da epistemologia não pode ser escrita apenas com a "retórica de la modernidad" (p. 9), mas a partir de novas leituras, como propõem os "enfoques decoloniales" (p. 9), ou seja, a partir da perspectiva da decolonialidade, num claro movimento de "resistencia epistemológica" (p. 9) e de "desobediencia epistémica" (p. 9), sobretudo quando se pensa em termos de educação. Assim, a proposta do livro é, em suma, analisar a diversidade da educação, a interculturalidade e o multiculturalismo pela chave decolonial, já que, segundo os próprios autores, “debemos educar para decolonizar, argumentar la esencia del currículo decolonial y de la didáctica decolonizante. Debemos abordar la enseñanza, el aprendizage y la evaluación desde la perspectiva de la decolonizalidad. Desde esta mirada, urge decolonizar da pedagogía, el currículo y la didáctica, pero urge también decolonizar la ciência, la epistemologia y la metodologia de la investigación" (p. 10).

No século XXI, explicam, emerge o que se poderia chamar de razão decolonial-pensar, nesse contexto, a decolonialidade da educação é pensar em uma Pedagogia Decolonial, diante da necessidade de re-pensar, re-educar e re-configurar o universo dos mais necessitados, sobretudo na América Latina e Caribe, desconstruindo a configuração colonial que, historicamente, tem marcado este espaço geográfico e humano. Assim, faz necessário, antes de tudo, diferenciarmos colonialismo (configuração de poder, exploração e dominação de uma região sobre outra, afirmando-se com a essência do imperialismo) e colonialidade (imposição sutil à subjetividade humana, mais enraizada, penetrante e prolongada, resultado do colonalismo, mas adquirindo autonomia e independência em relação a ele, articulando-se, inclusive, como domínio do conhecimento). Daí a urgência em se estabelecerem outros modos de conhecimento, num "proceso de reconfiguración epistémica" (p. 22), ou seja, "una configuración alternativa al occidentalismo, una perspectiva que cuestiona la modernidad eurocéntrica, no solo sus propuestas epistemológicas y epistémicas sino también de manera significativa su proyecto sociocultural y sus concepción de progreso, desarrollo y civilización, que nos han inpuesto durante más de 500 años” (p. 23).

Tendo como base a ideia (proveniente de Mignolo), de que a colonialidade é constitutiva - e não derivada - da modernidade, os intelectuais comprometidos com essa nova perspectiva (além de Mignolo, Quijano, Walsh, Dussel, Escobar, Maldonado, Castro-Gómez, Grosfoguel, Wallerstein e outros) reconhecem que, apesar de não mais existir o colonialismo clássico, permanece suas configurações subjetivas socioculturais, imaginários, crenças e percepções ligadas ao colonialismo, além de modelos de pensamento, teorias e ideologias eurocêntricas, 
portanto, persiste a colonialidade. Sendo a história da modernidade europeia uma história de autorreconhecimento, autoafirmação, de centralidade epistêmica e epistemológica, de imposição global, em que outras histórias foram silenciadas e apagadas, torna-se necessário, como contraponto a essa configuração da Europa como "centro cognitivo del mundo y del universo" (p. 26), um esforço conjunto no sentido de introduzir "epistemes invisibilizadas y subalternizadas" (p. 27), por meio de uma teoria da decolonialidade, baseada nas noções de interculturalidade e de diferença colonial.

A colonialidade, completam os autores, apresentam-se, ainda, sob diferentes tipos. Primeiro, a colonialidade do poder, relacionada à “occidentalización del otro" (p. 29), reconfigurando sua identidade e reorientando-a para um direcionamento eurocêntrico; segundo, a colonialidade do saber, relacionado à opressão, pelo colonizador, de outros saberes e outras maneiras de configurar o conhecimento, negando-se o legado epistêmico e histórico de outros povos não europeus; terceiro, a colonialidade do ser, direcionadas às relações humanas. Para combater essas formas de colonialidade, completam os autores, faz-se necessário transitarmos para da decolonialidade do viver, buscado um vida decolonial.

Buscando explicar ainda o conceito de decolonialidade, os autores destacam sua relação com a resistência e a insurgência, definindo-a nos seguintes termos: "la decolonialidad se refiere al proceso encaminado a trascender históricamente la modernidad/colonialidad. La decolonialidad no es un acto ni una actividad, no es un momento especifico de la lucha libertaria, es un proceso, una configuración de acciones biopráxicas que transitan mediante una deriva intencional caracterizada por la afluência del ser/hacer/saber/vivir, con un nível de profundidad jamás igualado por la descolonización" (p. 39). Diferentemente da colonização, a colonialidade encontra-se, ainda hoje, presente em nosso cotidiano como colonialidade do saber, do poder, do ser, do viver, motivo pelo qual torna-se imperativo a descolonização da vida, desprendendo-nos das "epistemes configuradas por el discurso eurocêntrico de Occidente" (p. 40). A colonialidade atinge assim todos os âmbitos da vivência humana, especialmente a linguagem, por meio do emprego de signos linguísticos "viciados", apontando ainda, nesse sentido, para a urgência de um processo de autodecolonialidade: "no hay justicia social y cultural sin justicia cognitiva e intelectual" (p. 41). Por isso, insistem os autores, a diferença entre descolonizar (superar uma situação de colonização) e decolonizar (assumir uma postura insurgente, reconfigurando formas e lugares de viver), sendo o primeiro um resultado e o segundo, um processo.

Ao tratarem especialmente da educação, no contexto acima exposto, os autores lembram que, ainda hoje, persiste uma perspectiva reducionista, estática, fragmentária e determinista da 
investigação educativa, revelando um atraso epistemológico, ontológico e metodológico evidente. Urge, portanto, edificar uma teoria da decolonialidade, baseada em autores seminais como Césaire, Fanon, Hall, Freire, Olivella e outros, recuando até autores dos séculos XVII (Felipe Ayala) e XVIII (Ottobbah Cugoano); presentemente, os autores que têm contribuído para a formulação desta teoria são Dussel, Mignolo, Quijano, Walsh, Castro-Gómez, Grosfoguel, Maldonado-Torres, Lander (colonialidade do saber), Tubino (interculturalidade crítica), Tuhiwai Smith (metodologias decolonizantes) e outros. Assim, pensar uma Pedagogia Decolonial é pensar a decolonização das práticas educativas, em direção a uma educação intercultural, a qual se vincula a uma crítica ao eurocentrismo, sobretudo o eurocentrismo pedagógico, curricular e didático, que traz arraigado em si uma lógica colonial: "Decolonizar la educación significa, entre otros argumentos, reconocer que los indígenas, campesinos, afros o sordos, vienen a la universidad no solo a aprender y transformarse sino también a enseñar. La decolonialidad de la educación se logra en la misma medida en que se reconoce la validez e importancia de los saberes 'otros' no oficializados por la matriz colonial”' (p. 78). Considerando que a colonialidade opera também nos sistemas educativos e nas teorias pedagógicas, torna-se imperativo, então, decolonizar a educação, sobretudo por meio de pedagogias 'outras', ao construir uma prática pedagógica baseada em "novos caminos espistémicos y epistemológicos (...) caminos fronterizos por donde transitar decolonialmente" (p. 83). Assim, a pedagogia decolonial refere-se a uma série de ações formativas que se constituem a partir de uma perspectiva decolonial: "si nosotros queremos desplegar biopráxis pedagógicas decoloniales, debemos hacerlo con la intencionalidad de configurar un pensamiento decolonial y, a su vez, estas pedagogias decoloniales exigem que los profesores desarrollemos nuestro pensamiento desde los bordes y la frontera, de ahí que uma condición sine qua non para el despliegue de biopraxis pedagógicas decoloniales es precisamente el desarollo de um pensamiento fronterizo y un posicionamento sustentado en la opción decolonial, de ahí que las configuraciones pedagógicas, curriculares y didácticas no pueden ser universales sino diversas, plurales y pluriversales" (p. 101).

Considerando o pensamento decolonial é uma autêntica teoría crítica latinoamericana y caribeña, os autores de Decolonialidad de la educación seguem de perto a ideia de uma de suas principais idealizadoras, para quem a aplicação da educação intercultural no contexto escolar requer compromisso e envolvimento amplo de todos (WALSH, 2005). Por esses e outros motivos, trata-se de uma obra que, mais do que conhecida, merece ser efetivamente aplicada no cotidiano da famigerada educação brasileira contemporânea. 


\section{Referências}

OCAÑA, Alexander Ortiz; LÓPEZ, María Isabel Arias; CONEDO, Zaira Esther Pedrozo. Decolonialidad de la educación. Emergencia/urgencia de uma pedagogía decolonial. Santa Marta, Universidad del Magdalena, 2018.

OLIVEIRA, Luiz Fernandes de. "O que é uma educação decolonial". Revista Nueva América, Buenos Aires, No. 149: 1-4, 2016.

WALSH, Catherine. La Interculturalidad en la Educación. Lima, Ministerio de Educación, 2005.

WALSH, Catherine; OLIVEIRA, Luiz Fernandes de; CANDAU, Vera Maria. "Colonialidade e Pedagogia Decolonial: para pensar uma educação outra". Arquivos Analíticos de Políticas Educativas, Arizona State University, Vol. 26, No. 83: 1-13, jul. 2018. 